\title{
ARTICLE OPEN HLA-mismatched allogeneic adoptive immune therapy in severely immunosuppressed AIDS patients
}

Ruonan Xu' ${ }^{1}$, Ji-Yuan Zhang ${ }^{1}$, Bo Tu${ }^{1}$, Zhe Xu${ }^{1}$, Hui-Huang Huang ${ }^{1}$, Lei Huang ${ }^{1}$, Yan-Mei Jiao ${ }^{1}$, Tao Yang ${ }^{1}$, Chao Zhang ${ }^{1}$, En-Qiang Qin ${ }^{1}$, Tian-Jun Jiang ${ }^{1}$, Yun-Bo Xie ${ }^{1}$, Yuan-Yuan Li ${ }^{1}$, Lei Jin ${ }^{1}$, Chun-Bao Zhou ${ }^{1}$, Ming Shi ${ }^{1}$, Mei Guo ${ }^{2}$, Hui-Sheng Ai $\mathbb{D}^{2}$, Linqi Zhang ${ }^{3}$ and Fu-Sheng Wang (iD)

Severely immunosuppressed AIDS patients with recurrent opportunistic infections (OIs) represent an unmet medical need even in the era of antiretroviral therapy (ART). Here we report the development of a human leukocyte antigen (HLA)-mismatched allogeneic adaptive immune therapy (AAIT) for severely immunosuppressed AIDS patients. Twelve severely immunosuppressed AIDS patients with severe Ols were enrolled in this single-arm study. Qualified donors received subcutaneous recombinant granulocyte-colonystimulating factor twice daily for 4-5 days to stimulate hematopoiesis. Peripheral blood mononuclear cells were collected from these donors via leukapheresis and transfused into the coupled patients. Clinical, immunological, and virological parameters were monitored during a 12-month follow-up period. We found AAIT combined with ART was safe and well-tolerated at the examined doses and transfusion regimen in all 12 patients. Improvements in clinical symptoms were evident throughout the study period. All patients exhibited a steady increase of peripheral CD4 ${ }^{+} \mathrm{T}$ cells from a median 10.5 to 207.5 cells/ $\mu$ l. Rapid increase in peripheral $\mathrm{CD}^{+}{ }^{+}$-cell count from a median 416.5 to 1206.5 cells/ $\mu$ l was found in the first 90 days since initiation of AAIT. In addition, their inflammatory cytokine levels and HIV RNA viral load decreased. A short-term microchimerism with donor cells was found. There were no adverse events associated with graft-versus-host disease throughout the study period. Overall, AAIT treatment was safe, and might help severely immunosuppressed AIDS patients to achieve a better immune restoration. A further clinical trial with control is necessary to confirm the efficacy of AAIT medication.

Signal Transduction and Targeted Therapy (2021)6:174

; https://doi.org/10.1038/s41392-021-00550-2

\section{INTRODUCTION}

Chronic human immunodeficiency virus (HIV)-1 replication leads to progressive loss of $\mathrm{CD}^{+} \mathrm{T}$ cells and immune disorders. Thus, acquired immune deficiency syndrome (AIDS) induced by chronic HIV-1 infection is not only a viral disease, but also an immunological illness. Combined antiretroviral therapy (ART) efficiently suppresses viral replication and promotes an increase in $\mathrm{CD}^{+}{ }^{+} \mathrm{T}$ cells, thereby reducing the mortality of AIDS patients, however it fails to efficiently resolve the immunological issues. ${ }^{1}$ As a result, AIDS patients undergoing ART still suffer from non-AIDSrelated events associated with systemic immune-mediated inflammation, ${ }^{2}$ and are often with low $\mathrm{CD}^{+}{ }^{+}$T-cell count even after 2 years of efficient ART. ${ }^{3}$ Furthermore, chronic HIV-1 infection can severely destroy the immune system, leading to extremely low $\mathrm{CD}^{+}{ }^{+}$T-cell counts $<50$ cells/ $\mu$ l. Such severely immunosuppressed AIDS patients are often diagnosed at late stage and suffer from intractable opportunistic infections (Ols), severe wasting syndromes, and other serious complications like immune response inflammation syndrome (IRIS). ${ }^{4-6}$

Due to the complication of Ols, some severely immunosuppressed AIDS patients cannot tolerate ART and have a higher likelihood of premature death. In last decade, more than $5 \%$ newly diagnosed HIV- 1 cases with baseline CD4 ${ }^{+}$T-cell counts $<50$ cells/ $\mu \mathrm{l}$ died in the first year in China. ${ }^{7}$ Therefore, even in the era of ART, more effective immune interventions are required for advanced AIDS patients, especially for severely immunosuppressed ones.

Complementary immune therapy against AIDS disease has been used since the early 1980s. For example, HLA-matched allogeneic lymphocyte transfusion was used to treat AIDS patients either alone or in combination with bone marrow transplantation. ${ }^{8-11}$ However, these early strategies were hampered by the lack of efficient antiretroviral agents and thus only resulted in a transient elevation in peripheral immunocyte microchimerism within 2-4 weeks. With the advent of ART in the 1990s, the survival rate greatly raised, particularly among AIDS patients with leukemia or lymphoma, primarily due to autologous or HLA-matched allogeneic hematopoietic stem cell transfusion (HSCT). Unfortunately, allogeneic HSCT is limited to AIDS patients with hematopoietic malignancies. ${ }^{12}$ The most successful examples are the "Berlin patient" and "London patient," who received both ART and homozygous CCR5 $\triangle 32$ allogeneic HSCT, finally achieved functional cure for AIDS and remission of their hematopoietic malignancies. ${ }^{13,14}$ However, given the rarity of HLA-identical donors with a CCR5 $\triangle 32$ homozygous genotype and associated life-threatening adversaries, such success is not replicable to the vast majority of patients in the routine clinical setting.

\footnotetext{
${ }^{1}$ Treatment and Research Center for Infectious Diseases, The Fifth Medical Center, PLA General Hospital, Beijing, China; ${ }^{2}$ Department of Hematology and Transplantation, The Fifth Medical Center, PLA General Hospital, Beijing, China and ${ }^{3}$ Comprehensive AIDS Research Center, School of Medicine, Tsinghua University, Beijing, China Correspondence: Fu-Sheng Wang (fswang302@163.com)

These authors contributed equally: Ruonan Xu, Ji-Yuan Zhang, Bo Tu, Zhe Xu
}

Received: 15 October 2020 Revised: 4 February 2021 Accepted: 26 February 2021

Published online: 07 May 2021 


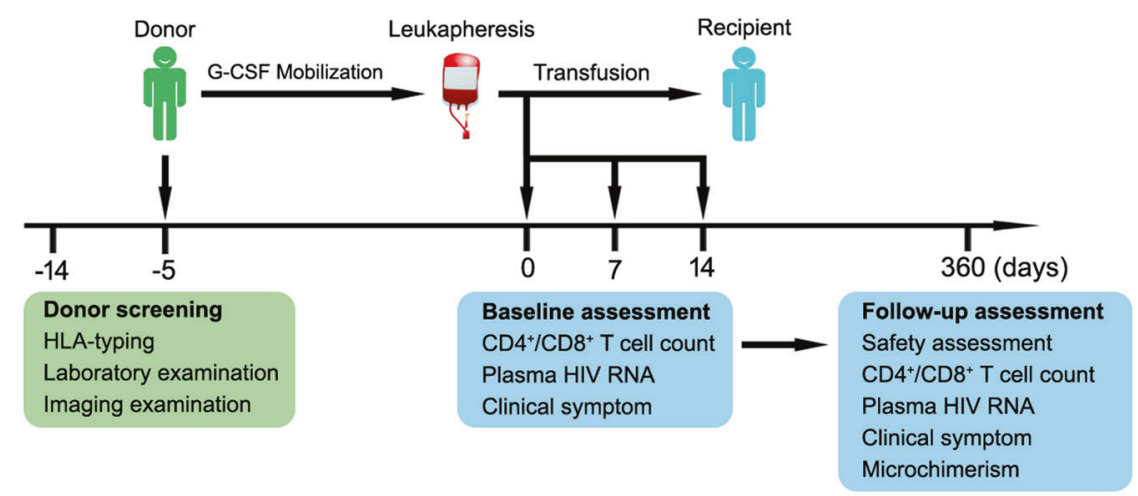

+ ART before AAIT $(n=7)$

$\longrightarrow \longrightarrow+$ ART after AAIT $(n=5)$

Fig. 1 Structure of the phase I, single-arm, AAIT study. AAIT was performed in 12 severely immunosuppressed AIDS patients. Seven patients received AAIT after ART, and five received AAIT before ART. Anti-OI treatments were given as necessary during the immunotherapy. G-CSF granulocyte-colony-stimulating factor, AAIT allogeneic adoptive immune therapy, Ols opportunistic infections, ART antiretroviral therapy

Recently, efforts have been made to explore genetically modified $\mathrm{CD}^{+} \mathrm{T}$ cells and HSCs from autologous or HLAmatched donors to restore the immune response in HIV-1infected patients. Participating patients are generally required to have a good response to ART and reasonable levels of $\mathrm{CD}^{+}{ }^{+} \mathrm{T}$-cell counts (usually $>200$ cells $/ \mu \mathrm{l}) .^{15-17}$ However, few treatment strategies are designed to treat severely immunosuppressed AIDS patients with $\mathrm{CD} 4{ }^{+} \mathrm{T}$-cell counts $<50$ cells $/ \mu \mathrm{l}$.

To address these issues, we developed a HLA-mismatched allogeneic adoptive immune therapy (AAIT) combined with ART regimen specifically tailored for severely immunosuppressed AIDS patients with $\mathrm{CD} 4^{+} \mathrm{T}$-cell counts $<50$ cells/ $\mu$ l. Here we present the safety and preliminary efficacy of this combined therapy.

\section{RESULTS}

Baseline characteristics of enrolled patients

A total of 12 severely immunosuppressed AIDS patients were enrolled in this proof-of-concept study (Fig. 1). The demographic and baseline information of these patients at enrollment is summarized in Table 1 . All patients had $\mathrm{CD}^{+}{ }^{+} \mathrm{T}$-cell counts well below 33 cells $/ \mu \mathrm{l}$, and 10 patients had counts $<20$ cells $/ \mu \mathrm{l}$. All patients presented two to five serious Ols, including pneumocystis carinii pneumonia, cryptosporidiosis, oral candidiasis, etc. Some patients had detectable cytomegalovirus (CMV) or Epstein-Barr virus (EBV) nucleic acid in the peripheral blood. No hepatitis $B$ virus (HBV) or hepatitis $C$ virus (HCV) nucleic acid was detected in any of the patients.

The majority of patients also presented with systemic constitutional symptoms such as intermittent or continuous fever $\left(38^{\circ} \mathrm{C}\right)$ for more than 1 month, repeated night sweats, debilitating fatigue, persistent diarrhea, and loss of body weight (Table 2). The plasma viral load ranged from undetectable to $1.76 \times 10^{7}$ copies $/ \mathrm{ml}$.

Anti-OI treatments were initiated according to current guidelines. ${ }^{18}$ Seven patients received the first-line ART regimen before AAIT; the remaining five patients received ART after AAIT, depending on their tolerance to the ART regimen.

AAIT is safe and well-tolerated

We selected 12 HLA-mismatched healthy donors and one HLAmatched donor from the relatives of the 12 patients (Supplementary Table 1) through determining their HLA haplotype on HLA-A, B, C; DRB1; and DQB1 alleles. After treatment with subcutaneous injection of recombinant human granulocyte-colony-stimulating factor (G-CSF) at $5 \mu \mathrm{g} / \mathrm{kg}$ twice daily for 4-5 consecutive days, when the total number of peripheral lymphocytes and monocytes exceeded $4.5 \times 10^{9}$ cells/L, donors were leukapherased to collect the G-CSF mobilized mononuclear cells (G-MNCs). Freshly collected mononuclear cells at an average dose of $3 \times 10^{8}$ cells/ $\mathrm{kg}$ (range $2.5-3.5 \times 10^{8}$ cells $/ \mathrm{kg}$ ) were transfused into the recipient on day 0 , while the remaining G-MNCs were aliquoted and stored in liquid nitrogen for later use. All patients received consecutive transfusions on day 7 and 14. Up to five rounds of transfusions were performed for some participating patients, depending on the need of the recipients and the availability of G-MNCs (Table 1).

G-CSF transfusion resulted in a significantly increased white blood (median value increased from $5.97 \times 10^{9} / \mathrm{L}$ to $42.15 \times 10^{9} / \mathrm{L}$ ) and neutrophil cell (median value increased from $3.60 \times 10^{9} / \mathrm{L}$ to $35.85 \times 10^{9} / \mathrm{L}$ ) in all healthy donors; a similar trend was observed for lymphocytes (median value increased from $1.65 \times 10^{9} / \mathrm{L}$ to $3.33 \times 10^{9} / \mathrm{L}$ ) and monocytes (median value increased from $0.30 \times$ $10^{9} / \mathrm{L}$ to $2.11 \times 10^{9} / \mathrm{L}$ ), albeit to a lesser degree. The components of infused G-MNCs were listed in Supplementary Table 2 in detail.

Over the 12-month follow-up period, AAIT was safe and welltolerated at the examined doses and transfusion regimens in all 12 patients. The criteria for monitoring adverse events (AEs) were accorded to Common Terminology Criteria for Adverse Events (CTCAE), any abnormalities after transfusion were carefully recorded. None of the patients experienced IRIS and only two had transient transfusion-related fever in the first $72 \mathrm{~h}$ after initiation of AAIT, which recovered quickly.

Improvements in clinical symptoms were evident throughout the study period, particularly in controlling the high fever, chronic diarrhea, weight loss, and serious pneumonia. For example, two patients (01-W and 02-Z) had persistent high fever, high frequency of diarrhea, and serious pneumonia before AAIT, these symptoms were significantly improved within 2-4 weeks after treatment (Fig. S1). In addition, five patients with wasting syndrome (01-W, 02-Z, 04-D, 08-D, and 09-L) improved significantly after AAIT, with substantial increases in appetite and weight gain. AIDS-related events and unscheduled hospitalization due to serious Ols were not found during follow-up (Table 2). Last, there was no acute (within 100 days) or chronic (within 360 days) graft-versus-host disease (GVHD) that occurred in skin, mouth, gastrointestinal tract, liver, and lung (Table 3). ${ }^{19,20}$

The levels of inflammatory cytokines were screened at days 0 , 30 and day 360 after AAIT. There was no significant increase of IL-6 and $\mathrm{IL}-8$, which were related to cytokine-release syndrome. ${ }^{21}$ Levels of IL-2, IL-4, IL-10, IL-17A, IFN-r, IP-10, CRP, MCP-1, GM-CSF, and SCD163 decreased over the 12-month study period, obviously within the first 30 days (Fig. S2). 


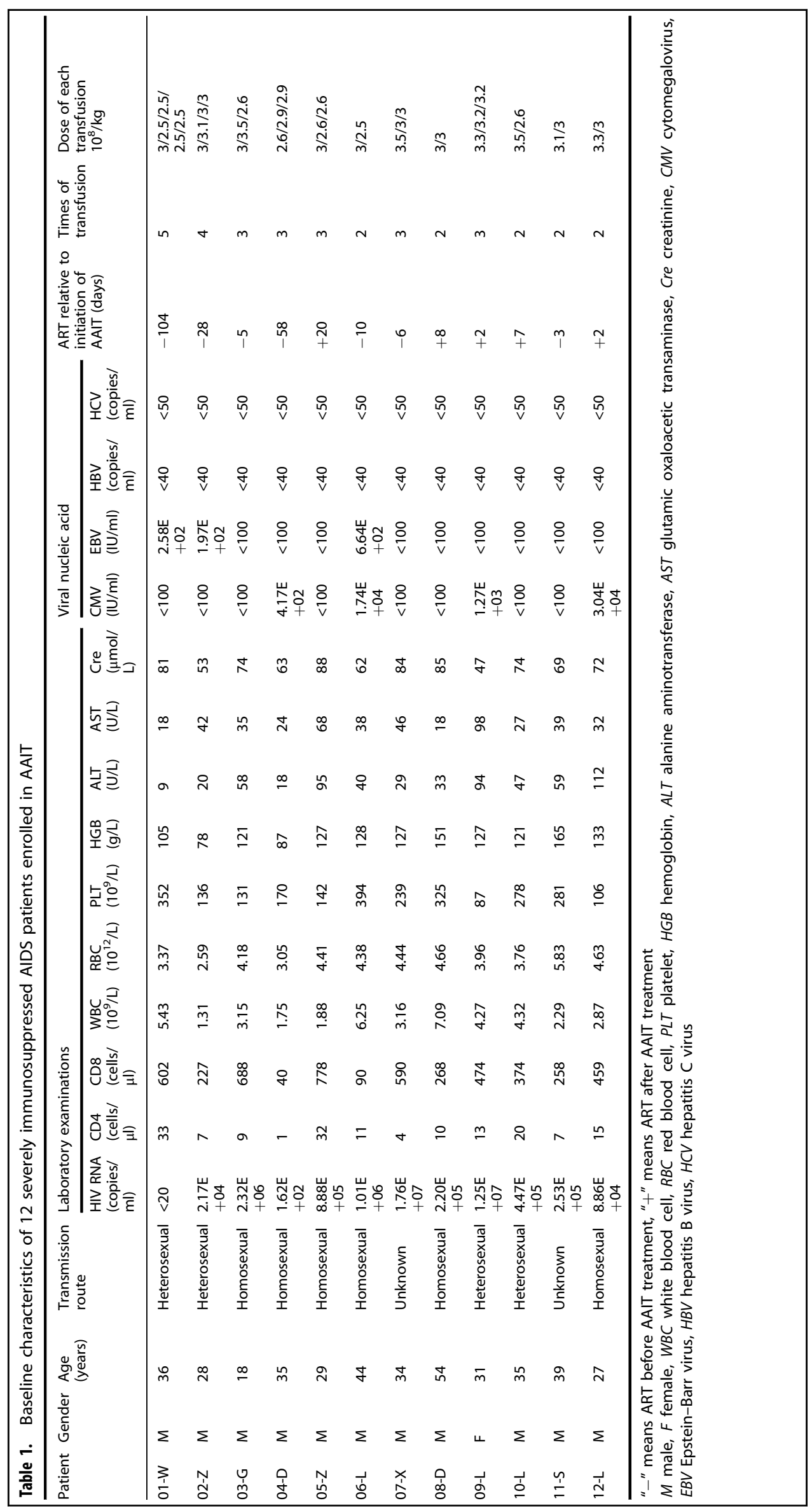


Table 2. AAIT improved clinical events and symptoms in the treated 12 patients

\begin{tabular}{|c|c|c|c|}
\hline \multirow[t]{2}{*}{ Patient } & \multicolumn{2}{|l|}{ Symptoms before AAIT } & \multirow{2}{*}{$\begin{array}{l}\text { Clinical response } \\
\text { after AAIT treatment }\end{array}$} \\
\hline & $\begin{array}{l}\text { AIDS-related events } \\
\text { at enrollment }\end{array}$ & $\begin{array}{l}\text { Systemic } \\
\text { constitutional } \\
\text { symptoms at } \\
\text { enrollment }\end{array}$ & \\
\hline $01-W$ & $\begin{array}{l}\text { Pneumonia } \\
\text { Sepsis } \\
\text { Crysptosporidiosis } \\
\text { EBV infection } \\
\text { Wasting syndrome }\end{array}$ & +++ & $\begin{array}{l}\text { No new } \\
\text { opportunistic } \\
\text { infections, } \\
\text { doing well }\end{array}$ \\
\hline $02-Z$ & $\begin{array}{l}\text { Pneumonia } \\
\text { Pulmonary abscess } \\
\text { Colitis } \\
\text { EBV infection } \\
\text { Wasting syndrome }\end{array}$ & +++++ & $\begin{array}{l}\text { Pulmonary abscess } \\
\text { significantly } \\
\text { improved within } \\
1 \text { month, doing well }\end{array}$ \\
\hline $03-G$ & $\begin{array}{l}\text { Pneumonia } \\
\text { PCP }\end{array}$ & ++ & $\begin{array}{l}\text { No new } \\
\text { opportunistic } \\
\text { infections, } \\
\text { doing well }\end{array}$ \\
\hline 04-D & $\begin{array}{l}\text { Pneumonia } \\
\text { CMV infection } \\
\text { Wasting syndrome }\end{array}$ & ++++ & $\begin{array}{l}\text { No new } \\
\text { opportunistic } \\
\text { infections, } \\
\text { doing well }\end{array}$ \\
\hline $05-Z$ & $\begin{array}{l}\text { Pneumonia } \\
\text { PCP } \\
\text { Oral candidiasis }\end{array}$ & ++ & $\begin{array}{l}\text { No new } \\
\text { opportunistic } \\
\text { infections, } \\
\text { doing well }\end{array}$ \\
\hline 06-L & $\begin{array}{l}\text { Pneumonia } \\
\text { PCP } \\
\text { CMV infection } \\
\text { EBV infection }\end{array}$ & ++ & $\begin{array}{l}\text { No new } \\
\text { opportunistic } \\
\text { infections, } \\
\text { doing well }\end{array}$ \\
\hline $07-X$ & $\begin{array}{l}\text { Pneumonia } \\
\text { PCP } \\
\text { Oral candidiasis }\end{array}$ & +++ & $\begin{array}{l}\text { Phlegmon occurs } \\
37 \text { days later }\end{array}$ \\
\hline 08-D & $\begin{array}{l}\text { Pneumonia } \\
\text { PCP } \\
\text { Oral candidiasis } \\
\text { Wasting syndrome }\end{array}$ & +++ & $\begin{array}{l}\text { No new } \\
\text { opportunistic } \\
\text { infections, } \\
\text { doing well }\end{array}$ \\
\hline 09-L & $\begin{array}{l}\text { Cryptosporidium } \\
\text { enteritis } \\
\text { Salmonella } \\
\text { typhimurium enteritis } \\
\text { Oral candidiasis } \\
\text { CMV infection } \\
\text { Wasting syndrome }\end{array}$ & ++++ & $\begin{array}{l}\text { No new } \\
\text { opportunistic } \\
\text { infections, } \\
\text { doing well }\end{array}$ \\
\hline $10-\mathrm{L}$ & $\begin{array}{l}\text { Pneumonia } \\
\text { PCP }\end{array}$ & ++ & $\begin{array}{l}\text { No new } \\
\text { opportunistic } \\
\text { infections, } \\
\text { doing well }\end{array}$ \\
\hline $11-S$ & $\begin{array}{l}\text { Pneumonia } \\
\text { PCP } \\
\text { Oral candidiasis }\end{array}$ & ++ & $\begin{array}{l}\text { No new } \\
\text { opportunistic } \\
\text { infections, } \\
\text { doing well }\end{array}$ \\
\hline $12-\mathrm{L}$ & $\begin{array}{l}\text { Pneumonia } \\
\text { PCP } \\
\text { Oral candidiasis } \\
\text { CMV infection }\end{array}$ & ++ & $\begin{array}{l}\text { No new } \\
\text { opportunistic } \\
\text { infections, } \\
\text { doing well }\end{array}$ \\
\hline
\end{tabular}

Clinical events and symptoms of 12 severely immunosuppressed AIDS patients were carefully recorded within 1 year after AAIT treatment. Systemic constitutional symptoms included intermittent or continuous fever $\left(38^{\circ} \mathrm{C}\right)$ for more than 1 month repeated night sweats, debilitating fatigue, persistent diarrhea, and a loss of body weight of more than $10 \%$, each " + " represents a symptom

$P C P$ pneumocystis carinii pneumonia, EBV Epstein-Barr virus, CMV cytomegalovirus

AAIT facilitates immune restoration and viral suppression During the 12-month follow-up period, we closely monitored the dynamic changes in $\mathrm{CD}^{+}$and $\mathrm{CD}^{+}{ }^{+}$-cell counts and plasma viral load. Median CD4 ${ }^{+}$T-cell counts increased from 10.5 to 207.5 cells/ $\mu$ l (Fig. 2a, b), while median $\mathrm{CD}^{+}{ }^{+}$T-cell counts increased from 416.5 to 1004 cells/ $\mu$ l (Fig. 2c, d). In addition, the median CD4/CD8 ratio raised from 0.032 to 0.164 (Fig. 2e, f).

To identify the source of these increased cells, we performed a microchimerism assay on the peripheral blood mononuclear cells up to 45 days after AAIT initiation. In most of the cases, microchimerisms peaked on day 1 , and then dropped suddenly, becoming undetectable by day 7 (Fig. S3). In one patient (02-Z) who received two rounds of transfusions, separately from a HLAmatched donor and a HLA-mismatched donor, the changes in microchimerisms appeared to be similar (i.e., peaking on day 1 , and then rapidly reducing in the ensuing days). However, compared to the HLA-matched infusion, the levels of microchimerisms were lower in the HLA-mismatched transfusion.

A significant drop in plasma viral load was found in all patients following the initiation of AAIT and ART. Two patients (02-Z and 06-L) switched ART treatment regimen from 3TC/TDF/EFV to 3TC/ AZT/DTG or $3 T C / A Z T / L P V / r$, respectively, due to drug resistance. Another two patients (01-W and 08-D) changed the regimen from 3TC/TDF/EFV to 3TC/TDF/LPV/r or 3TC/TDF/NVP, respectively, due to intolerance to EFV (Supplementary Table 3). Interestingly, AAIT appeared to exert antiretroviral activity, even without ART. For instance, patients $05-Z$ and $08-D$, who separately received ART 8 or 20 days after AAIT treatment, demonstrated more than one log decline in plasma viral load (Fig. 2h). Patient 10-L showed a slight increase in plasma viral load during the first 7 days after initiation of AAIT, but the viral load subsequently declined to undetectable level after 180 days. With these results, AAIT showed good safety and tolerability, as well as the ability to facilitate immune restoration and viral suppression in patients with $\mathrm{CD}^{+}$cell counts $<50$ cells $/ \mu$ l of blood.

\section{DISCUSSION}

There have been no safe and effective immune intervention that can be used alongside ART to address the unmet medical need for advanced AIDS patients, especially those severely immunosuppressed. We have successfully developed AAIT as an innovative regimen consisting of four successive procedures: (1) screening and selection of healthy donors; (2) mobilization with G-CSF; (3) GMNCs leukapheresis; and (4) G-MNCs transfusion. We have demonstrated that HLA-mismatched AAIT is not only safe and tolerable, but also contribute to improve the clinical symptoms as well as key immunological and virological parameters associated with AIDS-related events during this 12-month study. Therefore, AAIT represents a promising treatment strategy for immune restoration and virological suppression in advanced AIDS patients.

AAIT demonstrated impressive safety, tolerability, and feasibility, and contributed to rapid control of Ols. No serious AEs and no GVHD response were found in any patients throughout the study period, and no cytokine response storm associated with AAIT occurred. Among AAIT-treated patients, the common systemic symptoms including intermittent or persistent fever, repeated night sweats, debilitating fatigue, refractory diarrhea, and loss of body weight were significantly improved or completely disappeared; notably, the appetite and body weight were significantly increased. Through adoptive transferring a large number of neutrophils, $\mathrm{CD} 4^{+} \mathrm{T}$ and $\mathrm{CD} 8^{+} \mathrm{T}$ lymphocytes, natural killer (NK) cells, and monocytes from healthy donors, AAIT medication might reshape the whole immune environment and enhance the innate and adaptive immunity. In particular, AAIT in combination with ART may jointly contribute to a sustained increase of $\mathrm{CD}^{+}$T-cell count and the clinical benefits as mentioned above.

We also showed that AAIT facilitates both immune restoration and viral suppression. During the 1-year follow-up period, we found a substantial and steady increase in both $\mathrm{CD4} 4^{+}$and $\mathrm{CD} 8^{+}$ T-cell counts accompanied by a significant drop in plasma viral 


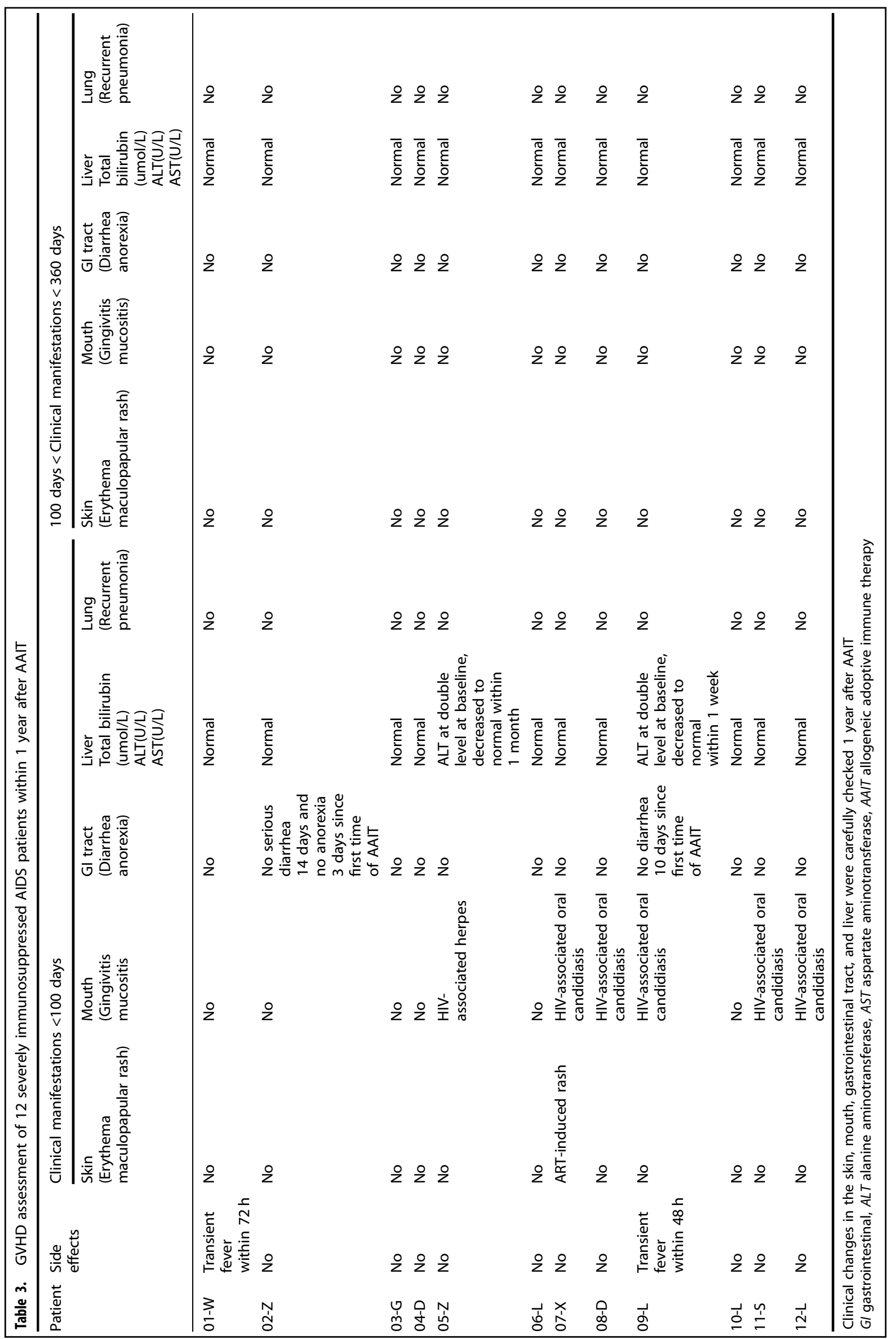



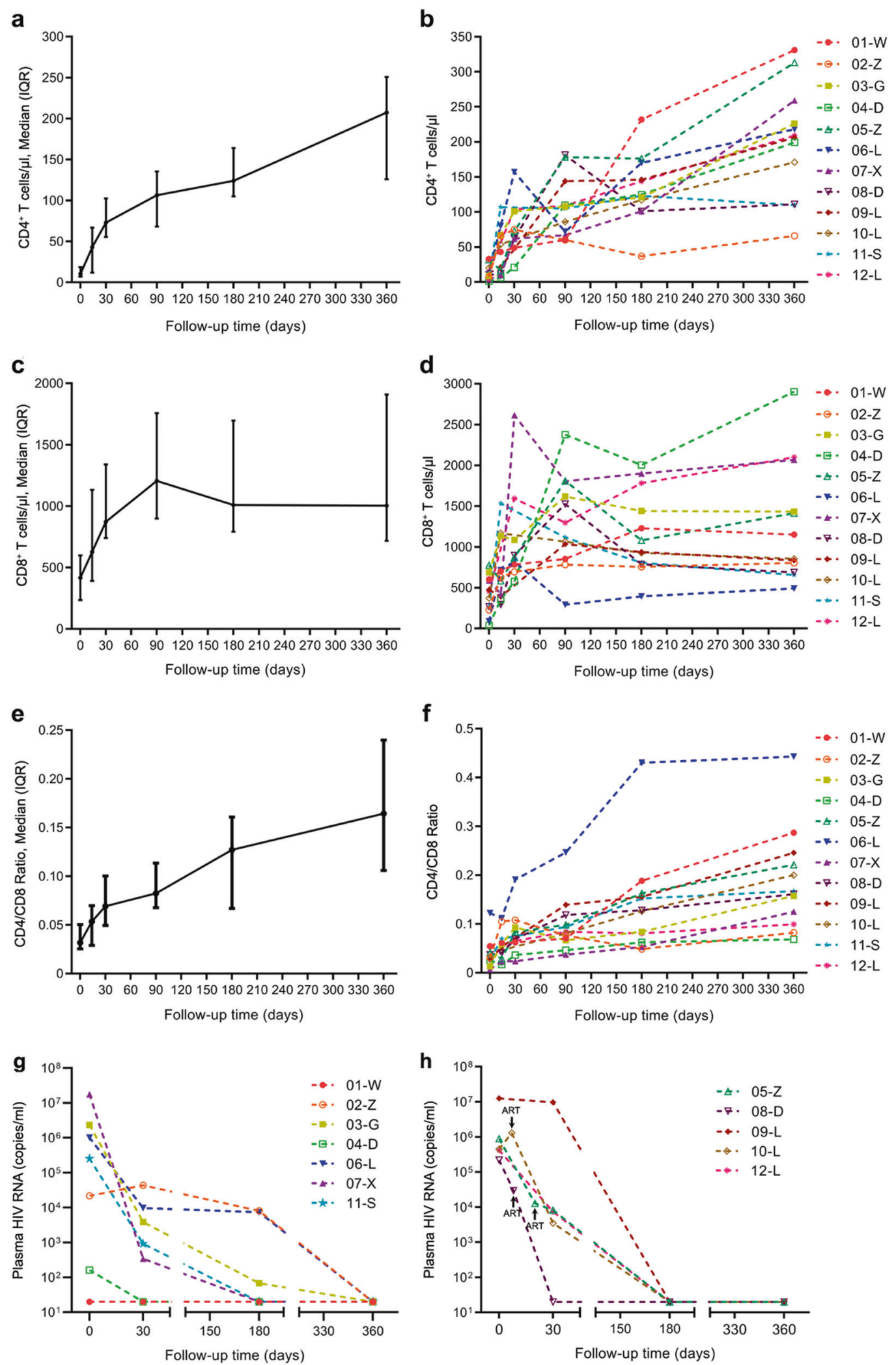

Fig. 2 Effects of AAIT on peripheral blood CD4+/CD8+ T-cell counts and HIV RNA in severely immunosuppressed AIDS patients. a The trend of $\mathrm{CD}^{+}$T-cell counts in severely immunosuppressed AIDS patients. b Changes in $\mathrm{CD}^{+}{ }^{+}$-cell counts in each of the 12 severely immunosuppressed AIDS patients. c The trend of $\mathrm{CD}^{+}$T-cell counts in severely immunosuppressed AIDS patients. $\mathbf{d}$ Changes in CD8 ${ }^{+}$T-cell counts in each of the 12 severely immunosuppressed AIDS patients. e The trend of CD4/CD8 ratio in severely immunosuppressed AIDS patients. $\mathbf{f}$ Changes in CD4/CD8 ratio in each of the 12 severely immunosuppressed AIDS patients. $\mathbf{g}$ The change of HIV RNA in patients receiving ART before AAIT $(n=7)$. $\mathbf{h}$ The change of HIV RNA in patients receiving AAIT before ART $(n=5)$. For patient $05-Z$, the AAIT was 20 days before ART. For patient 08-D, the AAIT was 8 days before ART. For patient 10-L, the AAIT was 7 days before ART. For the other two patients, the AAIT was 2 days before ART. The arrows represent the time of ART start 
load. But no transfusion-associated immune reconstitution inflammatory syndrome occurred in any of the patients owning to the swiftly recover of $\mathrm{CD}^{+}{ }^{+}$-cell count. Inflammatory-mediated cytokine levels also decreased within 30 days of AAIT. Moreover, a transient microchimerism with donor cells was found in recipients. Although the exact mechanism underlying immune restoration remains to be determined, the transient and low percentage of microchimerism in the recipients suggests the increased $\mathrm{CD}^{+}$and $\mathrm{CD}^{+} \mathrm{T}$ cells likely originate from the recipients' own cells. Interestingly, the microchimerism levels are higher and persist longer when HLA-matched donors are used compared to mismatched donors. Microchimerism levels also tended to decrease after repeated G-MNC transfusions. These results support the hypothesis that the host-versus-graft effect contributes to the immune restoration in the recipients. However, not every patient in our cohort demonstrated an improved CD4 ${ }^{+}$ T-cell count and the underlying reasons are currently unclear.

Our results also indicate that AAIT exerts antiretroviral activity, even without ART. Two patients who received ART after AAIT demonstrated a more than one log decline in plasma viral load. It is possible that infused $\mathrm{CD} 8^{+}$T cells, NK cells, or some other cell types exercise some nonspecific antiviral functions through modulating the patient's immune system. This finding is consistent with previous studies in which allogeneic treatment exerted a vigorous graft-versus-virus effect. ${ }^{22,23}$

Notably, our AAIT protocol does not use preconditioning, unlike the regimens used for hematopoietic malignant patients. ${ }^{11,12}$ This is primarily due to the unique clinical setting of severely immunosuppressed AIDS recipients who have almost complete eradication of adaptive and innate immunities, and lose the ability to reject the transfused allogenic G-MNCs from the donors. However, the underlying mechanisms need to be further studied.

There are some limitations in our proof-of-concept study. First, small cases were included and lacked a control group to determine whether combined AAIT/ART is better than ART monotherapy. Second, all patients were simultaneously accepted anti-Ols therapy, so it is unclear if these patients would have quickly recovered without the AAIT. Third, we also found that some AAIT-treated patients did not show improved $\mathrm{CD}^{+}{ }^{+} \mathrm{T}$-cell counts. Whether the efficacy of AAIT is influenced by the recipients' immune environment, their HLA status, or other reasons, requires further investigation.

In conclusion, we have developed a feasible and effective therapeutic regimen, named AAIT, for severely immunosuppressed AIDS patients. Our findings indicated that HLAmismatched AAIT is well-tolerated, and may contribute to restoration of the immune system in severely immunosuppressed AIDS patients. Following this phase 1 study, we have now embarked on a multi-center, open-labeled, phase 2 nonrandomized trial to assess the safety and efficacy of AAIT for the treatment of advanced AIDS patients (ClinicalTrials.gov Identifier: NCT 04098770).

\section{METHODS AND MATERIALS}

Study patients

A total of 12 severely immunosuppressed AIDS patients were enrolled in this single-armed clinical study from September 2015 to August 2017. The inclusion criteria were: (1) age 18-60 years, (2) severe immunodeficiency with HIV-1 infection and peripheral CD4 ${ }^{+}$ T-cell counts $<50$ cells/ $\mu l$, and (3) evidence of serious AIDS-related complications. Patients with the following features were excluded: (1) tumor and other serious organ diseases unrelated to AIDS, (2) allergy to blood products, or (3) under long-term immunosuppressive therapy. The baseline characteristics of the enrolled patients are listed (Table 1). Our study was approved by the ethics board of the Fifth Medical Center of the Chinese PLA General Hospital and all participating patients provided informed consent.
Development of the AAIT protocol

The AAIT protocol included four successive procedures: (1) screening and selection of healthy donors; (2) G-CSF mobilization; (3) G-MNCs leukapheresis; and (4) G-MNCs transfusion (Fig. 1). Healthy donors were selected from HLA-mismatched relatives of the enrolled AIDS patients through determining their HLA haplotype on HLA-A, B, C; DRB1; and DQB1 alleles. ${ }^{24-26}$ Physical examinations and laboratory tests were conducted for each donor, as previously described. ${ }^{24,25}$ Donors with virus infection (including HIV, hepatitis A virus, HBV, HCV, hepatitis E virus, EBV, CMV, and treponema pallidum) were excluded.

Qualified donors were treated with a subcutaneous injection of $5 \mu \mathrm{g} / \mathrm{kg}$ of rhG-CSF (HKyowa Hakko Kirin Co., Ltd), twice a day for 4-5 consecutive days. When the total number of peripheral lymphocytes and monocytes in the donors exceeded $4.5 \times 10^{9}$ cells/L, G-MNCs were obtained through leukapheresis by using a cell separator (COM.TEC, Fresenius Kabi), and the components of the GMNCs were analyzed by FACS analysis, as previously described. ${ }^{24,25}$ Fresh G-MNCs were used for the first transfusion in recipients individually on day 0 , and the remaining G-MNCs were divided into aliquots and stored in liquid nitrogen. On days 7 and 14 , about $3 \times$ $10^{8}$ cells $/ \mathrm{kg}$ (range, $2.5-3.5 \times 10^{8}$ cells $/ \mathrm{kg}$ ) of mononuclear cells were transfused. Based on the need of the recipients and the availability of G-MNCs, up to five rounds of transfusions were performed for some patients. The time and dose of each of the G-MNCs transfusions for each patient are summarized in Table 1.

Safety and efficacy assessments

The primary endpoint of our study was the safety assessment. Secondary endpoints focused on clinical, immunological, and virological improvement. The follow-up period after AAIT was 12 months for all participating patients. Clinical safety was assessed by physical and experimental examinations, the criteria for monitoring AEs were accorded to CTCAE. GVHD-associated symptoms were monitored throughout the entire study period, as previously described. ${ }^{27}$ Peripheral $\mathrm{CD}^{+}$and $\mathrm{CD} 8^{+}$T-cell counts, plasma HIV-1 RNA levels, cytokine profiles, the occurrence of Ols, and AIDS-related events were recorded during the entire study period. An independent safety monitoring committee reviewed the data and recorded all AEs during the study.

Monitoring of plasma HIV-1 RNA levels, and peripheral $\mathrm{CD}^{+}{ }^{+}$and CD8 ${ }^{+}$T-cell counts

COBAS AmpliPrep was used to quantify HIV-1 RNA levels in the plasma samples, as previously described. Trucount Tubes (BD Biosciences) were used to detect $\mathrm{CD}^{+}$and $\mathrm{CD} 8^{+}$T-cell counts in the peripheral blood. $^{28}$

Detection of cytokine profiles

Serum samples obtained before and after AAIT treatment were analyzed separately, cytokine profiles (IL-2, IL-4, IL-6, IL-8, IL-10, IL$17 \mathrm{~A}$, IFN-r, IP-10, MCP-1, and GM-CSF) were detected by using the Luminex Bio-Plex Pro Human cytokine assay with the Luminex 200 system. CRP and sCD163 were detected by the ELISA kit (R\&D Systems) according to the manufacturer's protocols at days 0,30 , and 360 .

Detection of the components of the G-MNCs by FACS array The components of the G-MNCs were stained by surface immunostaining with anti-CD3, CD34, CD45, CD4, CD8, CD19, CD16, CD56, CD25, and CD127 (BD PharMingen) antibodies, and analyzed using FACS Verse and FlowJo software (Tristar, San Carlos, CA), as previously described. ${ }^{24}$

\section{Detection of microchimerism}

Microchimerism was analyzed by real-time quantitative PCR for the detection of indel genomic polymorphisms in the peripheral blood samples with a sensitivity of $0.025 \%$ at different follow-up 
time points. ${ }^{29}$ Suitable DNA sequences, which were present in the donor and absent in the recipient, were selected.

Statistical analysis

This was a phase I, single-arm, proof-of-concept study. The data presented here represent the interquartile range of $\mathrm{CD} 4^{+} \mathrm{T}$ and $\mathrm{CD}^{+}$T-cell counts. The study was registered at ClinicalTrail.gov with number NCT02651376.

\section{DATA AVAILABILITY}

All of the data generated and analyzed during this study are included in our manuscript.

\section{ACKNOWLEDGEMENTS}

We would like to acknowledge all the participants in the trail. By grants from National Science and Technology Major Program (2018ZX10302104-002), Innovative Research Group Project of the National Natural Science Foundation of China (81721002). Peking University Clinical Scientist Program supported by "the Fundamental Research Funds for the Central Universities" (BMU2019LCKXJ013).

\section{AUTHOR CONTRIBUTIONS}

All authors made substantial contributions to this work. F.-S.W. proposed initial idea and study design. H.-S.A., R.X., J.-Y.Z., B.T., C.Z., and M.G. further co-designed the study protocol together. C.Z., B.T., H.-H.H., L.H., E.-Q.Q., T.-J.J., and Z.X. took care of patients and follow-up check. R.X., T.Y., Y.-B.X., and Y.-Y.L. responsible for protocol of AAIT cell preparation and quality control. J.-Y.Z., R.X., Y.-M.J., L.J., and M.S. collected the data and analyzed the data. Y.-M.J., R.X., J.-Y.Z., C.Z., and C.-B.Z. performed immunology assays. F.-S.W., L.Z., R.X., J.-Y.Z., and L.Z. co-wrote the manuscript including the figures and tables. All of the authors fulfill ICMJE criteria for authorship, and have access to all of the data in this study. All of the authors have read the paper and approved the final version submitted for publication.

\section{ADDITIONAL INFORMATION}

Supplementary information The online version contains supplementary material available at https://doi.org/10.1038/s41392-021-00550-2.

Competing interests: The authors declare no competing interests.

\section{REFERENCES}

1. Zhang, F. et al. Effect of earlier initiation of antiretroviral treatment and increased treatment coverage on HIV-related mortality in China: a national observational cohort study. Lancet Infect. Dis. 11, 516-524 (2011).

2. Zhang, F. et al. Five-year outcomes of the China National Free Antiretroviral Treatment Program. Ann. Intern. Med. 151, 1-42 (2015).

3. Gandhi, R. T. et al. Levels of HIV-1 persistence on antiretroviral therapy are not associated with markers of inflammation or activation. PLoS Pathog. 13, e1006285 (2017).

4. Masur, H. The acquired immunodeficiency syndrome. Dis. Mon. 30, 1-48 (1983).

5. Palella, F. J. et al. Declining morbidity and mortality among patients with advanced human immunodeficiency virus infection. HIV Outpatient Study Investigators. N. Engl. J. Med. 338, 853-860 (1998).

6. Spino, C., Kahn, J. O., Dolin, R. \& Phair, J. P. Predictors of survival in HIV-infected persons with 50 or fewer CD4 cells $/ \mathrm{mm}^{3}$. J. Acquir. Immune Defic. Syndr. Hum. Retrovirol. 15, 346-355 (1997).

7. Liu, J. et al. Immune restoration in HIV-1-infected patients after 12 years of antiretroviral therapy: a real-world observational study. Emerg. Microbes Infect. 9, 2550-2561 (2020).

8. Davis, K. C., Hayward, A., Oztürk, G. \& Kohler, P. F. Lymphocyte transfusion in case of acquired immunodeficiency syndrome. Lancet 1, 599-600 (1983).

9. Lane, H. C. et al. Partial immune reconstitution in a patient with the acquired immunodeficiency syndrome. N. Engl. J. Med. 311, 1099-1103 (1984).
10. Lane, H. C. et al. Syngeneic bone marrow transplantation and adoptive transfer of peripheral blood lymphocytes combined with zidovudine in human immunodeficiency virus (HIV) infection. Ann. Intern. Med. 113, 512-519 (1990).

11. Hassett, J. M., Zaroulis, C. G., Greenberg, M. L. \& Siegal, F. P. Bone marrow transplantation in AIDS. N. Engl. J. Med. 309, 665 (1983).

12. Hütter, G. \& Zaia, J. A. Allogeneic haematopoietic stem cell transplantation in patients with human immunodeficiency virus: the experiences of more than 25 years. Clin. Exp. Immunol. 163, 284-295 (2011).

13. Hütter, G. et al. Long-term control of HIV by CCR5 Delta32/Delta32 stem-cell transplantation. N. Engl. J. Med. 360, 692-698 (2009).

14. Gupta, R. K. et al. HIV-1 remission following CCR5 $\Delta 32 / \Delta 32$ haematopoietic stemcell transplantation. Nature 568, 244-248 (2019).

15. Duarte, R. F. et al. CCR5 $\Delta 32$ homozygous cord blood allogeneic transplantation in a patient with HIV: a case report. Lancet HIV 2, e236-e242 (2015).

16. Mitsuyasu, R. T. et al. Phase 2 gene therapy trial of an anti-HIV ribozyme in autologous CD34 ${ }^{+}$cells. Nat. Med. 15, 285-292 (2009).

17. $\mathrm{Xu}$, L. et al. CRISPR-edited stem cells in a patient with HIV and acute lymphocytic leukemia. N. Engl. J. Med. 381, 1240-1247 (2019).

18. Masur, $\mathrm{H}$. et al. Prevention and treatment of opportunistic infections in HIVinfected adults and adolescents: updated guidelines from the Centers for Disease Control and Prevention, National Institutes of Health, and HIV Medicine Association of the Infectious Diseases Society of America. Clin. Infect. Dis. 58, 1308-1311 (2014).

19. Sung, A. D. \& Chao, N. J. Concise review: acute graft-versus-host disease: immunobiology, prevention, and treatment. Stem Cells Transl. Med. 2, 25-32 (2013).

20. Filipovich, A. H. Diagnosis and manifestations of chronic graft-versus-host disease. Best. Pr. Res Clin. Haematol. 21, 251-257 (2008).

21. Maude, S. L. et al. Chimeric antigen receptor T cells for sustained remissions in leukemia. N. Engl. J. Med. 371, 1507-1517 (2014).

22. Wang, Y. et al. Allo-immunization elicits $\mathrm{CD}^{+} \mathrm{T}$ cell-derived chemokines, HIV suppressor factors and resistance to HIV infection in women. Nat. Med. 5, 1004-1009 (1999).

23. Shearer, G. M., Clerici, M., Graham, D. R. \& Boasso, A. Curing HIV/AIDS beyond hematopoietic stem cell transplant. AIDS 29, 2364-2366 (2015).

24. Guo, M. et al. Infusion of HLA-mismatched peripheral blood stem cells improves the outcome of chemotherapy for acute myeloid leukemia in elderly patients. Blood 117, 936-941 (2011).

25. Guo, M. et al. HLA-mismatched stem-cell microtransplantation as postremission therapy for acute myeloid leukemia: long-term follow-up. J. Clin. Oncol. 30, 4084-4090 (2012).

26. Huang, X. J. \& Chang, Y. J. Unmanipulated HLA-mismatched/haploidentical blood and marrow hematopoietic stem cell transplantation. Biol. Blood Marrow Transplant. 17, 197-204 (2011).

27. Barrett, A. J. et al. T cell-depleted bone marrow transplantation and delayed T cell add-back to control acute GVHD and conserve a graft-versus-leukemia effect. Bone Marrow Transplant. 21, 543-551 (1998).

28. Zhang, J. Y. et al. PD-1 up-regulation is correlated with HIV-specific memory CD8 ${ }^{+}$ T-cell exhaustion in typical progressors but not in long-term nonprogressors. Blood 109, 4671-4678 (2007).

29. Bach, C. et al. Monitoring of hematopoietic chimerism by real-time quantitative PCR of micro insertions/deletions in samples with low DNA quantities. Transfus. Med. Hemother. 42, 38-45 (2015).

Open Access This article is licensed under a Creative Commons Attribution 4.0 International License, which permits use, sharing, adaptation, distribution and reproduction in any medium or format, as long as you give appropriate credit to the original author(s) and the source, provide a link to the Creative Commons license, and indicate if changes were made. The images or other third party material in this article are included in the article's Creative Commons license, unless indicated otherwise in a credit line to the material. If material is not included in the article's Creative Commons license and your intended use is not permitted by statutory regulation or exceeds the permitted use, you will need to obtain permission directly from the copyright holder. To view a copy of this license, visit http://creativecommons. org/licenses/by/4.0/.

(c) The Author(s) 2021 